\title{
Plastic Solid Waste (PSW) in the Context of Life Cycle Assessment (LCA) and Sustainable Management
}

\author{
Ana Antelava ${ }^{1} \cdot$ Spyridon Damilos ${ }^{2} \cdot$ Sanaa Hafeez $^{1} \cdot$ George Manos $^{2} \cdot$ Sultan M. Al-Salem ${ }^{3} \cdot$ Brajendra K. Sharma $^{4}$. \\ Kirtika Kohli ${ }^{4}$. Achilleas Constantinou $\mathbb{1}^{1,2}$
}

Received: 25 July 2018 / Accepted: 3 June 2019 / Published online: 22 June 2019

(C) The Author(s) 2019

\begin{abstract}
Over the past few decades, life cycle assessment (LCA) has been established as a critical tool for the evaluation of the environmental burdens of chemical processes and materials cycles. The increasing amount of plastic solid waste (PSW) in landfills has raised serious concern worldwide for the most effective treatment. Thermochemical post-treatment processes, such as pyrolysis, seem to be the most appropriate method to treat this type of waste in an effective manner. This is because such processes lead to the production of useful chemicals, or hydrocarbon oil of high calorific value (i.e. bio-oil in the case of pyrolysis). LCA appears to be the most appropriate tool for the process design from an environmental context. However, addressed limitations including initial assumptions, functional unit and system boundaries, as well as lack of regional database and exclusion of socio-economic aspects, may hinder the final decision. This review aims to address the benefits of pyrolysis as a method for PSW treatment and raise the limitations and gaps of conducted research via an environmental standpoint.
\end{abstract}

Keywords Pyrolysis $\cdot$ Plastics $\cdot$ Sustainable Management $\cdot$ Recycling $\cdot$ Energy $\cdot$ LCA

\begin{tabular}{ll}
\multicolumn{2}{l}{ Abbreviations } \\
ADP & Abiotic Depletion Potential \\
AP & Acidification Potential \\
C-C & Carbon to Carbon \\
CED & Cumulative Energy Demand \\
CFB & Circulating Fluidized Bed \\
CH4 & Methane \\
CHP & Combined Heat and Power \\
CO2 & Carbon Dioxide \\
CO & Carbon Monoxide \\
CV & Calorific Value
\end{tabular}

Achilleas Constantinou constaa8@1sbu.ac.uk

1 Division of Chemical \& Petroleum Engineering, School of Engineering, London South Bank University, London SE1 0AA, UK

2 Department of Chemical Engineering, University College London (UCL), London WCIE 7JE, UK

3 Environment \& Life Sciences Research Centre, Kuwait Institute for Scientific Research, P.O. Box 24885, Safat 13109, Kuwait

4 Illinois Sustainable Technology Center, Prairie Research Institute, University of Illinois, Urbana-Champaign, 1 Hazelwood Dr., Champaign, IL 61820, USA
EIA Environmental Impact Assessment

EP Eutrophication Potential

EU European Union

FU Functional Unit

GHG Greenhouse Gas

GWP Global Warming Potential

$\mathrm{HCl}$ Hydrogen Chloride

HF Hydrogen Fluoride

HHV Higher Heating Value

H2S Hydrogen sulphide

HTP Human toxicity potential

ISO International Standards Organisation

LCA Life Cycle Assessment

LCEA Life Cycle Energy Analysis

LCI Life Cycle Inventory

LCIA Life Cycle Impact Assessment

MPW Municipal Plastic Waste

MSW Municipal Solid Waste

MRF Material Recovery Facilities

NMVOC Non-Methane Volatile Organic Compound

NH3 Ammonia

NOx Nitrogen Oxides

N2O Nitrous Oxide

ODP Ozone Depletion Potential

PAHs Polycyclic Aromatic Hydrocarbons 


$\begin{array}{ll}\text { PCDD } & \text { Polychlorinated Dibenzo Para Dioxins } \\ \text { PCDF } & \text { Polychlorinated Dibenzo Furans } \\ \text { PE } & \text { Polyethylene } \\ \text { PET } & \text { Polyethylene Terephthalate } \\ \text { PLA } & \text { Polylactic Acid } \\ \text { PMMA } & \text { Polymethylmetacrylate } \\ \text { PO } & \text { Polyolefin } \\ \text { POCP } & \text { Photochemical Ozone Creation Potential } \\ \text { POFP } & \text { Photochemical Oxidant Formation Potential } \\ \text { PP } & \text { Polypropylene } \\ \text { PS } & \text { Polystyrene } \\ \text { PSW } & \text { Plastic Solid Waste } \\ \text { PU } & \text { Polyurethanes } \\ \text { PVC } & \text { Polyvinyl Alcohol } \\ \text { RDF } & \text { Refuse-Derived Fuel } \\ \text { SDLC } & \text { Software Development Life Cycle } \\ \text { SOx } & \text { Sulphur Oxides } \\ \text { SPCR } & \text { Sequential Pyrolysis and Catalytic Reforming } \\ \text { SS } & \text { Sewage Sludge } \\ \text { SW } & \text { Solid Waste } \\ \text { TCT } & \text { Thermo-Chemical Treatment } \\ \text { TEA } & \text { Techno-Economic Assessment } \\ \text { VOCs } & \text { Volatile Organic Compounds } \\ \text { WTP } & \text { Well-To-Pump } \\ \text { WTT } & \text { Well-To-Tank }\end{array}$

\section{Introduction}

Production of plastics has increased drastically over the past century, from a mere 1.3 million tonnes in 1950 to $>322$ million tonnes in 2015 (PE 2016). A global increase of plastics consumption is also noted with a rate of $4 \%$ per annum (Miandad et al. 2016). The associated cost of managing plastic solid waste (PSW) drives several countries and communities alike to discard it in open landfill sites. This leads to the accumulation of plastic commodities and articles as a major component in the solid waste (SW) stream. PSW is bulkier than other organic refuse, thus occupies larger space in landfills. Various advances occurred within the past three decades in SW recycling and valorisation. Regardless, $\sim 9.5 \%$ of the total plastic produced over the period from 1950-2015 has been recycled, while $12.5 \%$ has been incinerated and $78 \%$ is still discarded in landfills (Geyer et al. 2017).

PSW can be categorised depending on its source or point of origin, i.e. municipal, industrial, medical, etc. However, the majority of PSW is generated from households and commercial sources, which combined, are referred to as municipal plastic waste (MPW). This type of SW mainly consists of the following plastic resin types: polyethylene (PE), polypropylene (PP), polystyrene (PS), polyethylene terephthalate (PET) and polyvinyl alcohol (PVC) (Miandad et al. 2017). MPW is typically thermoplastics, which are thermally recyclable due to their non-resistance to heat. According to the ISO 15270 (2008), PSW can be recycled and treated to produce raw materials, and the production of high calorific compounds can be used as fuels for energy production. MPW is treated by an ascending order of preference from reprocessing and extrusion, to recovering utilities and energy. For example, mechanical recycling results in plastic pelletization and subsequently raw plastic materials. On the other hand, chemical recycling processes lead to polymer cracking, to monomers allowing the production of polymers and fuels. The management of PSW in general will rid the environment of the accumulation of PSW, and prevent pollution problems from landfilling, such as toxins leaching that can contaminate ground water aquifers (Al-Salem et al. 2015).

Incinerating $\mathrm{SW}$ has become a popular choice of treatment as a waste-to-energy (WtE) management technology. Nevertheless, incineration of PSW is reported to cause air and groundwater pollution problems related to the plastic type and content in the waste, as well as the process conditions, due to the emissions of GHG, SOx, particles, volatile organic compounds (VOCs) and polycyclic aromatic hydrocarbons (PAHs) (Al-Salem et al. 2009). The European Union (EU) has established permissible emission limits and guidelines described in the Council Directive 2000/76/EC. It was also previously concluded that different thermoplastics result in varying levels of PAH post treatment via incineration (Li et al. 2001). Typically, PE and PP will result in high PAH levels measured in the flue gas of incineration units, although PVC will have higher levels of PAHs in the bottom ash recovered rather than the flue gas. This is attributed to the fact that PVC will decompose at higher temperatures at a stage where the additives to the resin will coagulate in the ash.

It is well noted at this stage of technical development, that environmental impacts of processes are divided into three main categories, namely as energy related, climate change related and eco-toxicological impacts (Lazarevic et al. 2010). In case of plastics with significant chlorine content, incineration causes the formation and emission of dioxins and furans, such as polychlorinated dibenzo para dioxins (PCDD) and polychlorinated dibenzo furans (PCDF) (Lazarevic et al. 2010). Process conditions are of major importance as incomplete combustion of the PSW could lead to the formation of carbon monoxide (CO) and smoke (Verma et al. 2016). In case of high nitrogen content plastics, such as polyurethanes (PU), incineration could lead to excess emissions of nitrogen oxide (NO) and nitrogen dioxide $\left(\mathrm{NO}_{2}\right)$, with a dramatic increase of the global warming potential (GWP) (Al-Salem et al. 2009). Thus, 
various thermo-chemical treatment (TCT) methods such as hydrogenation, gasification and pyrolysis became important for the management of MPW (Nizami et al. 2015).

Pyrolysis presents several advantages for treating PSW, namely solid plastics originating from the municipal sector. Pyrolysis involves the degradation of the constituting polymers of the plastic materials by heating them in inert (non-reactive) atmospheres. The process is typically conducted at temperatures between $350-900^{\circ} \mathrm{C}$ and produces carbonized solid char, condensable hydrocarbon oil and a high calorific value (CV) gas. The product's selectivity and yields of product fractions depend on the plastic type along with process conditions (Al-Salem et al. 2017). It is divided into two main types, thermal (without the presence of catalysts) and catalytic pyrolysis. Thermal pyrolysis produces liquids with low octane value and higher residue contents at moderate temperatures (Seth and Sarkar 2004). The gaseous products obtained by thermal pyrolysis typically require upgrading to be used as a fuel (Panda et al. 2010). Pyrolysis can also be conducted catalytically; reducing the temperature and reaction time required for the process and allowing the production of hydrocarbons with a higher $\mathrm{CV}$ value such as fuel oil (Almeida and Marques 2016). The presence of catalysts in pyrolysis also aids the evolution of gasoline and diesel range products (Aguado et al. 2000) and gives an added value to pyrolysis. The cracking efficiency of these catalysts depends on their chemical and physical characteristics. These properties promote the breaking of carbon to carbon $(\mathrm{C}-\mathrm{C})$ bonds and determine the length of the chain of the obtained products.

One of the main aims of the EU environmental policies is to integrate the environmental sustainability with economic growth (Tarantini et al. 2009). There is an environmental concern about the increase in conventional PSW management by mechanical means, and whether it is the most sustainable practice. These concerns are due to high energy demands around various European communities. Decision makers need to evaluate technical, environmental and economic aspects of waste management techniques. Environmental impact assessment (EIA) and inventory analysis are prime examples of such techniques. However, life cycle assessments (LCA) can provide a more in-depth framework to evaluate the waste management strategies, identify environmental impacts and hot spots with respect to the waste treatment hierarchy. LCA evaluates environmental burdens and potential impacts associated with processes, by gathering an inventory of inputs and outputs and interpreting the results of the study.

To perform state-of-the-art LCA studies for PSW technologies, a systematic overview of assessment processes is required. The aim of this review is to provide such an overview based on the existing LCA studies of PSW processes reported in literature. In particular, a comprehensive review and analysis of the pyrolysis process is evaluated in context of its environmental performance through LCA. The associated benefits and burdens of this process are detailed and reported from an LCA standpoint. This was done to be able to compare various scenarios that have incorporated pyrolysis to valorise PSW. This work can also aid decision makers (and takers) in understanding the benefits associated with pyrolysis. Various research gaps are detailed and showcased for the reader's consideration. To the best of the author's knowledge, no such work has been attempted in the past.

\section{Plastic Waste Management Options and Processes}

Table 1 provides a list of the major advantages and disadvantages for the main plastic waste management techniques. The major practicing routes for disposing waste plastics are; landfill, mechanical recycling, and energy recovery (Al-Salem et al. 2009; Lazarevic et al. 2010). Recycling and reuse are not suitable for all waste streams, thus a great amount of MSW ends up in landfills and wasteto-energy (WtE) plants (Margallo et al. 2018). Gu et al. (2017) has investigated the life cycle of mechanical plastic recycling in China. The results have shown that mechanical recycling is a superior alternative in most environmental aspects, compared with the production of the virgin plastics. Virgin composite production has an impact which is almost four times higher than that of the recycled composite production ( $\mathrm{Gu}$ et al. 2017). Despite odorous emissions released during meltdown of waste plastics and soil contaminations, mechanical recycling is generally an environmental-friendly approach for waste plastic disposal.

Municipal solid waste incineration is another robust waste treatment method, which not only reduces waste volume but also allows for the efficient recovery of energy. However, it requires high construction, installation and maintenance costs (Margallo et al. 2018). Gasification process involves the heating of the feedstock materials under a controlled amount of oxygen to produce synthesis gas without fully oxidizing the feedstock to carbon dioxide. The synthesis gas can then be used to generate power or heat or be converted by catalytic Fisher-Tropsch synthesis to hydrocarbons (Benavides et al. 2017). Several LCA studies have compared the MSW treatment techniques such as landfill, combustion, gasification to pyrolysis. This analysis agrees that the pyrolysis technique offers more environmental benefits, such as reduction of GHG emissions and consumption of fossil fuels (Benavides et al. 2017).

Pyrolysis is a thermal decomposition process of organic materials in the absence of oxygen into char, oil and gas (Sheth and Babu 2009, Wang et al. 2015). An oxygen-free 


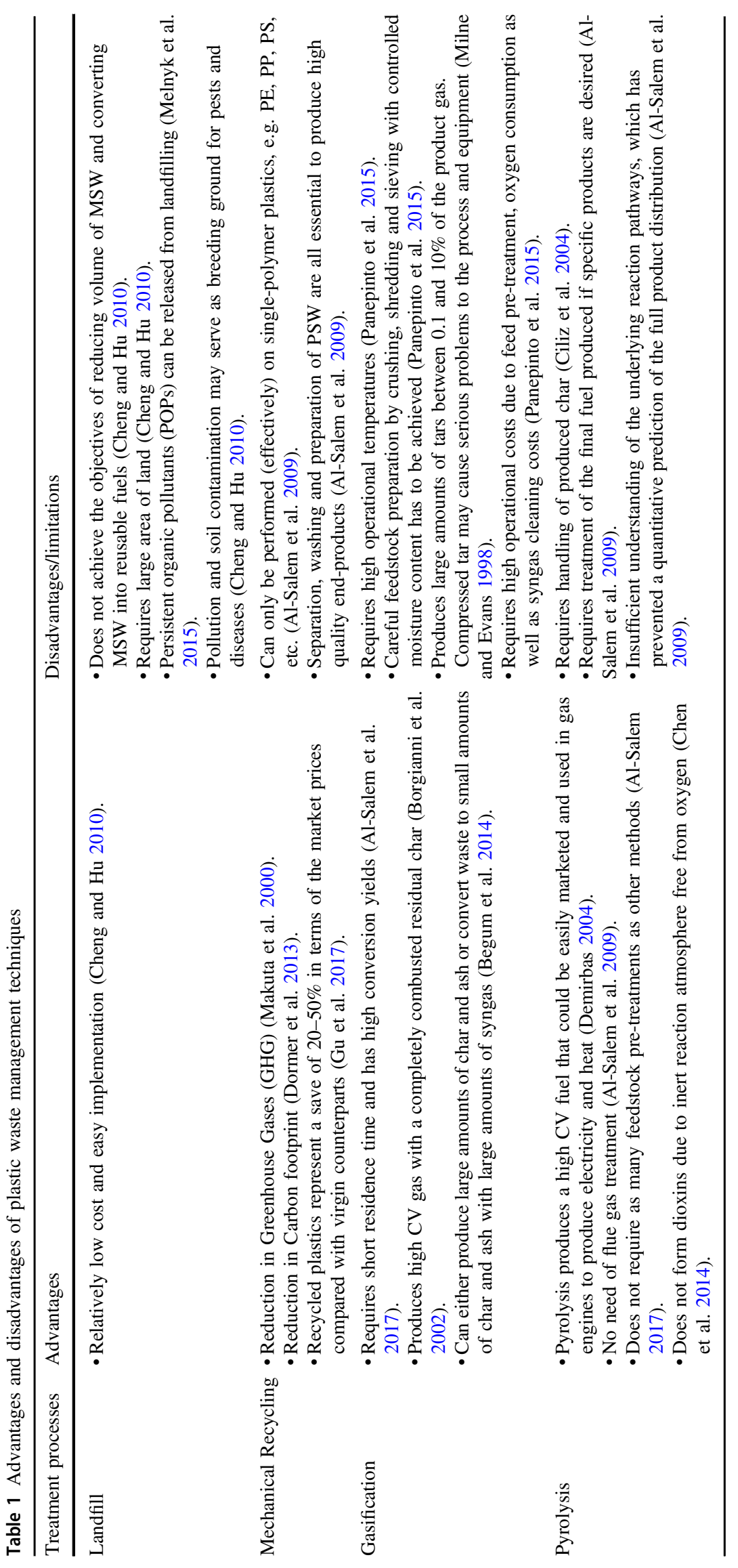


environment prevents the oxidation of the hydrocarbon which would have reduced the heating values of the product fuel. The proportion of the pyrolysis products such as liquid fuel, gas and char depends on the feedstock composition as well as the conditions of the process (Benavides et al. 2017). The produced liquid oil can have many applications, for example, it can be used as an energy source. Its potential use as a transport fuel source might require further upgrading and blending with diesel to improve its characteristics, as it contains a high number of aromatics. The use of pyrolysis oil, together with diesel as transport fuel, was successfully tested at different ratios in past research (Demirbas 2004; Gardy et al. 2014; Islam et al. 2010, Miandad et al. 2017). Another product of pyrolysis is char. Char produced from PS plastic wastes has a higher heating value (HHV) of $36.29 \mathrm{MJ} / \mathrm{kg}$ (Syamsiro et al. 2014), therefore it has the potential to be used as an energy source. Several researchers have activated pyrolysis char using steam (Lopez et al. 2011), hydrogen peroxide (Heras et al. 2014) or by thermal activation (Jindaporn and Lertsatitthanakorn 2014). Activation of char increases its surface area that improves the ability to adsorb the heavy metals, odours and toxic gases (Miandad et al. 2017).

Over the past year there have been several case studies on the life-cycle assessment of waste treatment (plastic, municipal, etc.), or biomass treatment via pyrolytic methods for energy or fuel production. Demetrious and Crossin (2019) have examined and compared the waste treatment via landfill, incineration and gasification-pyrolysis showing the importance of pyrolysis on reducing the greenhouse gas (GHG) potential, although landfill method requires less energy and is preferred to gasification-pyrolysis route. It is noteworthy that they provide an insightful discussion on the limitations of the LCA methodology of this study, which is related to the geographical scope, the electricity mix assumed, as well as the limitation of the LCA on the environmental impacts associated with plastic reaching out in the natural environment causing micro-plastic ingestion and marine entanglement. Finally, their study paved the way for policy amendment on the waste management.

Vienescu et al. (2018) studied the use of pyrolysis to produce synthetic fuels via an LCA approach. Despite the promising results, similar LCA studies must consider the wide range of environmental impacts that occur during the synthesis production. This is due to the rise of environmental burdens in comparison to the diesel and petrol production processes. Therefore, the materials used in system construction, as well as different allocation methods for stover and pyrolysis by-products, need to be investigated for their environmental and socioeconomic trade-offs. Barry et al. (2019) conducted an environmental and economical analysis on municipal sewage sludge via pyrolysis. Based on their findings, the two pyrolysis scenarios performed better than the incineration scenarios with respect to the impact categories of global warming potential, and freshwater ecotoxicity, with the use of the biochar as a coal substitute offering the greatest greenhouse gas reductions.

Khoo (2019) assessed PSW recovery into recycled materials, energy and fuels in Singapore through LCA. The waste treatment options included mechanical recycling, pyrolysis and gasification. The work highlights the normalisation and weighting factors on the LCA analysis in accordance to the relative importance of environmental impacts and sustainability indicators. Different normalization methods can be applied which will result in different outcomes, and weighting factors can also be influenced by altered political views or agendas, geographical settings, environmental regulations, or even cost. Therefore, LCA results are biased on the system boundaries and the weighting factors considered in the analysis.

Gear et al. (2018) developed a toolkit for process design via LCA, focusing on the thermal cracking process for mixed plastic waste. The case study focused on the products of recycling technologies process; however, the toolkit performs hotspot analysis and multivariable optimization that includes environmental performance across the entire range of possible weighting. Their result indicates the importance of integrating process optimization with environmental impact assessment via data analysis and LCA.

Several companies utilise different waste management technologies, in order to, convert PSW to fuel and other valuable products. Within the European Economic Area (EEA) agreement countries, there is a significant number of industrial partners that utilise thermal waste-to-fuel (WtF) technologies including Cynar plc, Plastoil, Promeco, Syngas Products Group, Plastic Energy, Recycling Technologies and Enval Ltd (Haig et al. 2017). Amongst these companies, Syngas Products Group Ltd focuses on nonrecyclable waste feedstock to energy, while utilising a combined process of pyrolysis-gasification for the synthesis of renewable gas of high calorific value. The company's plant in Canford, Dorset (UK) has a capacity of $10 \mathrm{ktpa}$ of PSW feedstock input with a $0.8 \mathrm{MWe}$ unit for power generation. The company also plans to expand and scale up the facility to $100 \mathrm{ktpa}$ input and $8 \mathrm{MWe}$ output (Syngas Products Group 2019). They established a fully commercial plastic liquefaction facility on the island of Hokkaido. Plastic Energy Co. has a patented thermal anaerobic conversion technology aimed at converting PSW into feedstock for plastics production or alternative low-carbon fuels. The company has two recycling plants in Seville and Almeria (Spain) which have been in operation since 2014 and 2017, respectively. For every tonne of end-of-life PSW processed, 850 litres of chemical pyrolysis oil (TACOIL) is produced. The company aims to process 200,000 tonnes of plastic by 2020 (Plastic Energy 2019). 
Recycling Technologies have developed a process methodology for plastic recycling via converting the plastic waste to fuel and its capacity reaching up to 9000 tpa. They have also commercialised four special ultra-low sulfur oils (reaching less than $0.1 \%$ sulfur content) derived from recycled plastics - called Plaxx — which can be used as a fuel substitutes or feedstocks to produce plastics or wax (Recycling Technologies 2019). Enval ltd. focuses on microwaveinduced pyrolysis to process plastic aluminium laminates. Recycling aluminium through the Enval process leads to energy savings of up to $75 \%$. With a purity exceeding $98 \%$ and a minimum metal yield of $80 \%$, it can be directly reintroduced to the resmelting process. A typical Enval plant produces 200-400 tonnes of aluminium a year. The generated pyrolytic oils can be used as chemical feedstock or for energy generation. The Enval process can be controlled to adjust yield of the gases and oils according to the operator's requirements. Enval plants can operate at a feed rate of up to $350 \mathrm{~kg}$ per hour, which equates to a nominal capacity of 2000 tonnes per year (Enval 2019). Etia Ecotechnologies has developed an innovative patented pyrolysis process Biogreen $^{\circledR}$ that is operating since 2003 (ETIA Group 2019).

In addition, a significant number of companies based in the United States of America (USA) perform pyrolysis to produce fuel from plastics, such as Agilyx (2019), Global Renewables and Vadxx, Climax Global Energy, Envion, Plastic Advanced Recycling Corp, Plastic2Oil and PolyFlow (Haig et al. 2017). Agilyx was founded in 2004 and is based in Oregon, USA. It has operated as a pyrolysis plant that processes rigid PSW to recycle plastics into low carbon synthetic crude oil, and in 2018 opened a polystyrene to styrene monomer facility (Butler et al. 2011). The Vadxx plant is utilising no-recyclable plastic to produce fuel via continuous pyrolytic process. The company has a plant in Ohio, USA of 25,000 tonnes plastic annual capacity, to produce solid (solid carbon-based fuel), liquid (naptha and diesel) and synthetic gas fuels (Bailey 2014). Biogreen ${ }^{\circledR}$ The Plastic2Oil Inc. has developed their own in-house technology that derives ultra-clean, ultra-low sulphur fuel that does not require further refining from waste plastic. The conversion ratio of the waste plastic into fuel is about $86 \%$ with $2-4 \%$ of the resulting product being Carbon Black. The company reports that the process' emissions are lower than that of a natural gas furnace of the similar size (Plastic2oil 2019). Pyrolysis is used worldwide for as a waste-tofuel thermal treatment technology, including the Sapporo Plastic Recycling establishing a fully commercial plastic liquefaction facility on the island of Hokkaido in 2000 with the scale to recycle 50 tonnes of mixed plastic waste a day (Klean Industries 2019). Other notable companies utilising pyrolysis for the waste-to-fuel process are Anhui Orsun Environmental Technologies, Blest, Dynamotive and Niutech Energy Ltd (Haig et al. 2017).
In the United States more than 137 million tons of MSW were landfilled back in 2015, out of which 26.01 million tons was plastic waste (US EPA 2019). Pyrolysis has the potential to decrease the use of landfills as an MSW management technique by $19 \%$ and decrease the consumption of conventional fuels. According to the figures reported by Plastic Energy, each tonne of end-of-life plastic PSW processed, 850 litres of chemical feedstock (pyrolysis oil) TACOIL is produced (Plastic Energy 2019). According to report by 4R Sustainability, Inc. (2011) one ton of MSW produces 264 gallons of consumer-ready fuel (around 1000 litres of pyrolysis oil). The average consumption of petroleum is 20.5 million barrels per day in the United States (Eia.gov 2019). Converting landfilled plastics into pyrolytic oil could reduce the petroleum consumption by $1.8 \%$ as well as reduce the air and water contamination. The GHG emissions associated with the use of waste plastics as a feedstock depend on the use from which that plastic is diverted. The bio-oil production from biomass pyrolysis may have other environmental impacts, for example increasing greenhouse gas (Bringezu et al. 2009). Products from PSW pyrolysis are also unpredictable at times and depend of the feedstock type. Hence, life cycle assessments must be conducted to identify the overall environmental impact of pyrolysis (Wang et al. 2015). The use of municipal solid waste (MSW) for oil and energy production instead of landfilling has a positive effect on the greenhouse gas emissions (GHG) equilibrium. Wang et al. (2015) examined the GHG emissions for both options-pyrolysis and landfilling of the MSW-resulting to $79 \%$ reduction of the GHG emissions when MSW were transferred to a fast pyrolysis plant for treatment. In addition, Gunamantha (2012) investigated the environmental impact for different scenarios of MSW treatments showing that incineration resulted in reducing the $\mathrm{GHG}$ from $374 \mathrm{~kg} \mathrm{CO}_{2-\mathrm{eq}} / \mathrm{tMSW}$ for landfilling to $61 \mathrm{~kg} \mathrm{CO}_{2-\mathrm{eq}} / \mathrm{tMSW}$ for incineration while energy recovery was estimated at $291 \mathrm{kWh}$ in the latter case. Stepanov et al. (2018) examined the reduction of the environmental burden when MSW were sent for incineration instead of landfilling, showing that the GHG were reduced from $2.69 \times 10^{7} \mathrm{~kg} \mathrm{CO}_{2 \text {-eq }} /$ year to $1.22 \times 10^{5} \mathrm{~kg}$ $\mathrm{CO}_{2-\mathrm{eq}}$ /year. On the other hand, the study of Demetrious and Crossin (2019) regarding the treatment of mixed plastics showed that the GHG via gasification-pyrolysis were $1.87 \mathrm{~kg} \mathrm{CO}_{2-\mathrm{eq}} / \mathrm{kg}$ processed, in comparison to the $0.0151 \mathrm{~kg} \mathrm{CO} \mathrm{Ceq}_{-\mathrm{eq}} / \mathrm{kg}$ processed emissions via landfilling, due to the large impact of the direct emission and the electricity. Similarly, the study of Zaman (2013) concluded that the global warming potential of pyrolysis-gasification process of the MSW was $1000.153 \mathrm{~kg} \mathrm{CO}_{2-\mathrm{eq}} / \mathrm{tMSW}$ compared with the $40.04723 \mathrm{~kg} \mathrm{CO}_{2-\mathrm{eq}} / \mathrm{tMSW}$ in case of landfill, despite the benefits for energy production via pyrolysis of the MSW. These results could be related to the GHG impact 
of the harmful residue of the pyrolytic process leading to productions of carbon dioxide and carbon monoxide during decomposition of final residue.

\section{LCA Standard Methodology, Description and Limitations}

One of the techniques developed to assess and evaluate the possible environmental impacts of products and processes is LCA. It is an internationally standardized method that has been developed from chemical engineering principles and energy analysis (Hertwich et al. 2002). The International Standard of ISO $14040(1997 ; 2006)$ regulates the practice and describes the principles, methodology and framework for conducting LCA and assists in identifying the parameters to improve the environmental aspects of products at various points in their life cycle. The analysis considers any option that influences the environment by consuming resources and releasing emissions which consequently generate waste streams. Generally, the impacts that are considered include resource use, human health and ecological impacts. LCA is an effective decision-making technique for waste management and treatment processes (Rigamonti et al. 2009). ISO 14040 (2006) defines the four basics for conducting an LCA study thus;

1. Goal and scope definition; where the objectives are defined and the extent of the study and the functional unit (FU) are set within the boundaries of the system.

2. Life cycle inventory (LCI) or Inventory Analysis: In this stage, mass and energy balances are developed and the inputs/outputs of the system are defined.

3. Life cycle impact assessment (LCIA): The impact and burdens are evaluated in this stage with a set magnitude and value with the aid of impact indicators.

4. Life cycle interpretation: This is the final stage where the study is systematically evaluated and conclusions with respect to scope and FU are derived.

The LCA system boundaries establishes the processes included within the supply chain of fuel or products. The system boundaries must account for time, space and the functional unit (FU) chosen as a basis of comparison (Eriksson et al. 2002). It is paramount to distinguish between the 'foreground' system and the 'background' system. The former being a set of processes whose selection or mode of operation is affected directly by decisions based on the study (in this case waste management activities), whilst the latter is defined as all other processes that interact with the foreground system, usually by supplying or receiving materials and energy (Fig. 1).

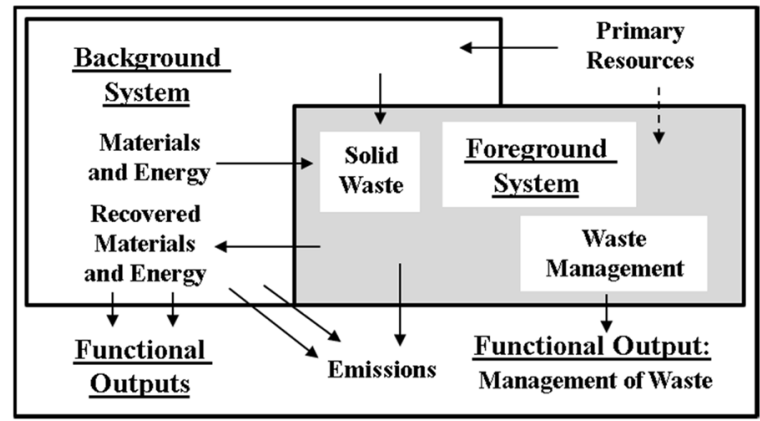

Fig. 1 Foreground and Background systems used explicitly by the EA (UK). Source: Clift et al. (2000)

LCA is conducted by establishing an inventory of inputs and outputs of the production system, assessing their potential environmental consequences, and interpreting the results in relation to the objectives of the assessment. However, the system boundary, initial assumptions and the FU chosen may affect the results interpretation and render comparison between LCA studies impossible. Results of global and regional LCA studies differ and might not appropriately represent the local conditions. Thus, comparing LCA studies is only possible if the assumptions and context of each study are the same. LCA has some limitations and is not a universal assessment technique. Typically, LCA does not account for the economic or social aspects of a product. Nevertheless, the international standards organisation (ISO) has released further guidelines over the LCA methodology by introducing the 14070 Standard series, such as the ISO 14071 (2014) and ISO 14072 (2014). The new guidelines account for additional requirements over the previous ISO 14066 (2011) as far as organization are concerned in reporting LCA results. Economical or socioeconomical categories are now encouraging and assigned to numerical values in such cases. Factors such as visual pollution, odours, noise, destruction of the natural habitat, etc., are likely to be excluded from an LCA analysis, although these factors are important and must be considered in the decision-making process (Arena et al. 2003).

LCA methodology has been used for a variety of different systems and processes as a decision-making tool. LCA can be applied various assessment approaches, regarding the studied system and the system boundaries considered. Well-To-Wheel (WTW), Well-To-Pump (WTP) or Well-To-Tank (WTT) methodologies are used by the energy and fuel production sector to describe and assess the environmental impact of fuels, taking into account the use of product (that is WTW) or only the upstream process up to fuel storage before use (that is WTP). Collet et al. (2013) reviewed the environmental impact of biodiesel synthesis from microalgae considering both WTW and WTP 
analyses. Their analysis relied on the GHG and energy balance of the studied systems, excluding the social and economic aspects. However, they insisted on the importance of a common functional unit and system boundaries to allow comparison among the studied systems for assessments of similar scope and aim. The Joint Research Centre of EU released a technical report on the WTT and WTP pathways of different petroleum-derived fuels and biofuels, based on the ISO 14040 series Standards, establishing common LCA pathway analyses and comparison methodologies for the EU region. Cabeza et al. (2014) depicted LCA case studies for the building industry, and they implemented an extension by considering direct and indirect energy demands and cost analysis. Regarding the construction industry, fundamental LCA methodology focuses on the cradle-to-grave analysis and end-of-life recycling of the construction material, assessing the environmental impact of the construction. Through Life Cycle Energy Analysis (LCEA), energy demands were also included in the environmental and sustainability study. The study of Laurent et al. (2014a, 2014b) showed that LCA studies are dependent on the location and the local regulations, hindering the comparison between different life cycle assessments. The most common LCA analyses concerns cradleto-gate and cradle-to-grave systems. These studies include the process from material extraction to disposal or recycling, respectively.

Madival et al. (2009) focused on a cradle-to-cradle LCA comparison between poly(lactic acid) (PLA), poly(ethylene terephthalate) (PET) and poly(styrene) (PS) as packaging materials, in which the analysis concerned the process from material extraction until disposal, and use for energy production or material replacement by recycling. In their study they focused on the GWP and the eco-toxicity burdens, as well as land occupation, showing that transportation stages of the materials had the major environmental impact and thus should be considered in the system boundaries of the LCA studies. Blengini et al. (2012) studied the credibility and acceptability of the LCA results, that are influenced by methodological assumptions and the local socio-economic constraints. The average consumption of petroleum is 20.5 million barrels per day in the United States (Converting landfilled plastics into pyrolytic oil could reduce the petroleum consumption by $1.8 \%$.

\section{LCA Studies in Context of Plastic Solid Waste Management}

Different software (computerized-aided solutions) systems are used to design and conduct the LCA studies for the pyrolysis process used for the plastic solid waste managements. The most commonly used for the research projects and technical assessments are reported in Table 2. Table 3 shows the avoided burdens via different waste management treatments of MSW, while Table 4 summarises major findings of some of the main published results of LCA studies encompassing PSW as part of the studied material flow. According to the published findings, thermochemical treatment could result to a sustainable solution for plastic solid waste management, due to the low values of all environmental burdens for all chosen FU.

Song and Hyun (1999) conducted LCA study on the various recycle routes of PET bottles. Mathematical models for the waste (including PSW) recycling systems have been developed using the energy and material balances on each operation involved. The Jacobian matrix of partial derivatives representing the sensitivity of each environmental burden was used for an analysis. Khoo (2009) evaluated eight waste treatment technologies in Singapore. The impacts analysed were GWP, AP, terrestrial eutrophication and ozone photochemical formation. The greatest impacts were caused by the thermal cracking gasification of granulated MSW and the gasification of refuse-derived fuel (RDF), while the least were from the steam gasification of wood and the pyrolysis-gasification of MSW. The most cost-effective technique was identified to be the circulating fluidized bed (CFB) gasification of organic waste and the combined pyrolysis, gasification and oxidation of MSW.

Rigamonti et al. (2009) have analysed the material and energy recovery within MSW management systems to evaluate the most efficient and environmental results. Simapro 7 software, developed by PRè Consultants was used for the evaluation. Two characterisation methods were used; the cumulative energy demand (CED) and CML 2. CED investigates the energy demand of the process to estimate the total energy demand. Negative estimations are typically more favourable as they indicate the system studied is in credit (Al-Fadhlee and Al-Salem 2015). CML 2 is an LCA method developed by the CML (Centrum voor Milieuwetenschappen - Centre of Environmental Sciences, an institute of the Faculty of Science of Leiden University), it evaluates the environmental impacts through the process's life. Several environmental impacts were considered such as; global warming potential (GWP), human toxicity potential (HTP), acidification potential (AP) (emissions of NOx, SOx and ammonia) and photochemical ozone creation potential (POCP). Three MSW integrated management systems were analysed, differing in the quantities of waste sent to material recovery and to energy recovery routes. The source separated collection scenarios were taken as 35,50 and $60 \%$. The results obtained showed that the optimum source-separated collection is $60 \%$ as the materials are recovered with high efficiency.

Iribarren et al. (2012) used LCA to evaluate the performance of the sequential pyrolysis and catalytic reforming 
(SPCR) of PE wastes. The objectives of the study were to assess environmental and energy characterization of the system, identify the processes with the highest contributions to the potential impacts, and compare the performance of the SPCR system with conventional waste management techniques such as landfilling and incineration. Seven impact potentials were considered for evaluation; CED, abiotic depletion (ADP), AP, eutrophication (EP), GWP, ozone layer depletion (ODP), and photochemical oxidant formation (POFP). The result showed that the traditional hierarchical approach is accurate as the recycling and recovery were identified as better options compared with conventional plastic waste treatments; landfilling and incineration. The SPCR products showed lower impacts in all categories except GWP (for gasoline and diesel) compared with products from the conventional techniques. Minimising the direct emissions would improve the GWP.

Gunamantha (2012) analysed five municipal solid waste treatment scenarios; landfilling system with energy recovery, a combination of incineration and anaerobic digestion, combined gasification and anaerobic digestion, direct incineration, direct gasification. These scenarios were compared with the existing landfilling system. In the study, gas emissions such as $\mathrm{CO}_{2}, \mathrm{CO}, \mathrm{CH}_{4}, \mathrm{~N}_{2} \mathrm{O}, \mathrm{NO}_{2}, \mathrm{NH}_{3}$, $\mathrm{SO}_{2}, \mathrm{H}_{2} \mathrm{~S}, \mathrm{HF}, \mathrm{HCl}$, and NMVOC were selected as the objects for assessment and were allocated into impact categories; GWP, AP, eutrophication, and photochemical oxidant formation. In terms of global warming, eutrophication and photochemical oxidant production direct gasification was identified to be the most feasible with savings of $168 \mathrm{~kg} \mathrm{CO}_{2} \mathrm{eq} / \mathrm{FU}, \quad 0.17 \mathrm{~kg} \mathrm{PO}_{4} \mathrm{eq} / \mathrm{FU}$, and $0.16 \mathrm{~kg}$ ethylene eq/FU, respectively. While in terms of acidification, gasification and anaerobic digestion gave the highest value of saving $2.8 \mathrm{~kg} \mathrm{SO}_{2} \mathrm{eq} / \mathrm{FU}$.

Al-Salem et al. (2014a) evaluated the waste management system in the Greater London area using the GaBi software. Waste produced in Greater London was sent to a dry materials recovery facility and to an incineration unit with combined heat and power production. This waste treatment technique was compared with a landfill scenario and the study showed that the actual waste management system in Greater London has a lower environmental impact than the landfilling. The paper also analysed two alternative technologies; pyrolysis and hydrogenation. The use of hydrogenation resulted in the highest savings in terms of eutrophication potential due to avoided naphtha production. In a follow-up study and implementing the same methodology, PO PSW was used as a feedstock to a pyrolysis process for the State of Kuwait in Al-Salem (2014b). The waste feedstock used has reduced both the GWP and AP by over $30 \%$ for the whole country when compared with the baseline scenario and in a combination to incineration for energy recovery. The LCA also confirmed that sustainable 
Table 3 Avoided burdens considered for different case studies of waste management treatments of MSW

\begin{tabular}{|c|c|c|}
\hline Source & Waste management technique & Avoided burdens \\
\hline Eriksson et al. (2005) & $\begin{array}{l}\text { Incineration } \\
\text { Incineration with biological treatment } \\
\text { Incineration with material recycling } \\
\text { Landfilling }\end{array}$ & Consumption of primary energy production \\
\hline $\begin{array}{l}\text { Eriksson and Finnvedenb } \\
(2009)\end{array}$ & Incineration & Use of fossil fuels for electricity and heat from a CHP unit \\
\hline Bovea et al. (2010) & $\begin{array}{l}\text { Recycling } \\
\text { Biological treatment } \\
\text { Landfilling }\end{array}$ & $\begin{array}{l}\text { Use of virgin materials } \\
\text { Use of fertilisers and electrical energy } \\
\text { Electrical energy }\end{array}$ \\
\hline $\begin{array}{l}\text { Fruergaard and Astrup } \\
\text { (2011) }\end{array}$ & $\begin{array}{l}\text { Co-combustion of solid recovered fuels } \\
\text { Anaerobic digestion } \\
\text { Incineration }\end{array}$ & $\begin{array}{l}\text { Use of fossil fuels for electricity and heat from a CHP unit } \\
\text { Use of fossil fuels for electricity, heat and transportation and } \\
\text { fertilisers by the digestate fraction. } \\
\text { Use of fossil fuels for electricity and heat from a CHP unit }\end{array}$ \\
\hline Iribarren et al. (2012) & $\begin{array}{l}\text { Sequential pyrolysis and } \\
\text { catalytic reforming }(\mathrm{SPCR}) \\
\text { Incineration } \\
\text { Landfilling }\end{array}$ & Refinery gas, gasoline, diesel \\
\hline Al-Salem et al. (2014a) & $\begin{array}{l}\text { Incineration and materials recovery } \\
\text { facility (MRF) } \\
\text { Low temperature pyrolysis } \\
\text { Vea Combi-Cracking hydrogenation reactor }\end{array}$ & $\begin{array}{l}\text { Production of steam from natural gas and electricity from the grid. } \\
\text { Production of virgin plastics, glass and steel from the MRF } \\
\text { Petrochemical-based commercial products and production of steam } \\
\text { from natural gas } \\
\text { Commercial products from produced chemicals }\end{array}$ \\
\hline Wang et al. (2015) & Pyrolysis & Coal, natural gas, diesel, gasoline \\
\hline
\end{tabular}

management can be achieved for the studied systems since products can replace those of the largest refinery in the country in an integrated manner.

Later, Wang et al. (2015) have investigated the environmental impacts of an MSW pyrolysis plant in North Carolina (USA). LCA was conducted to assess the environmental impacts of production, upgrading and usage of bio-oil from MSW using GaBi software. The impacts of pyrolysis were compared with anaerobic digestion, incineration and landfilling for MSW. Pyrolysis for bio-oil was identified to have the least impact, while the landfilling for treating the MSW causes the most undesirable impact on the environment. Evangelisti et al. (2015) compared the environmental impacts of three dual-stage technologies; gasification and plasma gas cleaning, pyrolysis and combustion and gasification with syngas combustion. These techniques were compared with conventional MSW treatments which were landfilling with electricity production and incineration with electricity production. Results show that the two-stage gasification and plasma process has better environmental performance than the conventional techniques and modern incineration plant, which was demonstrated by a plant in Lincolnshire (UK). The advantage of gasification with plasma process is mainly from the higher net electrical efficiency. It should be noted that the gasification gas combustor process has a GWP of $0.18 \mathrm{~kg} \mathrm{CO}_{2} \mathrm{eq} /$ $\mathrm{kWh}$ (electrical production). This accounts for only $30 \%$ of the Sheffield incineration plant and $75 \%$ of the North Hykeham incineration plant. The result of the study showed that the two-stage gasification and plasma process is more environmental solution for the MSW treatment compared with incineration processes, for all the impact categories taken into the account.

Chen et al. (2019) conducted the environmental, energy and economic analysis of integrated treatment of MSW and sewage sludge (SS) in China. Four scenarios were studied including mono-incineration of MSW (Case 1) and SS (Case 2), co-incineration of SS and MSW by traditional (Case 3) and integrated ways (Case 4), by means of LCA, CED and TEA method. It was found that Case 4 had the most optimistic effect on climate change and resources ( $-1.44 \mathrm{~kg} \mathrm{CO}_{2 \text {-eq }}$ and $-18 \mathrm{MJ}$, respectively) corresponding to the end-point categories. From an energy perspective, Case 4 demonstrated the most desirable performance of energy efficiency, and significantly saves non-renewable energy ( 0.21 t coal per ton feedstock compared with Case 3 ). From an economics point of view, Case 4 is preferred with the best profit, reducing $79.08 \%$ of cost in coal than that in Case 3. It was concluded that these results provide an understanding of developing an effective approach for cotreating MSW and SS.

Ardolino et al. (2018) conducted a study providing a Life Cycle Inventory model for the fluidised bed gasification of wastes. All the data had been obtained from a pilot scale 


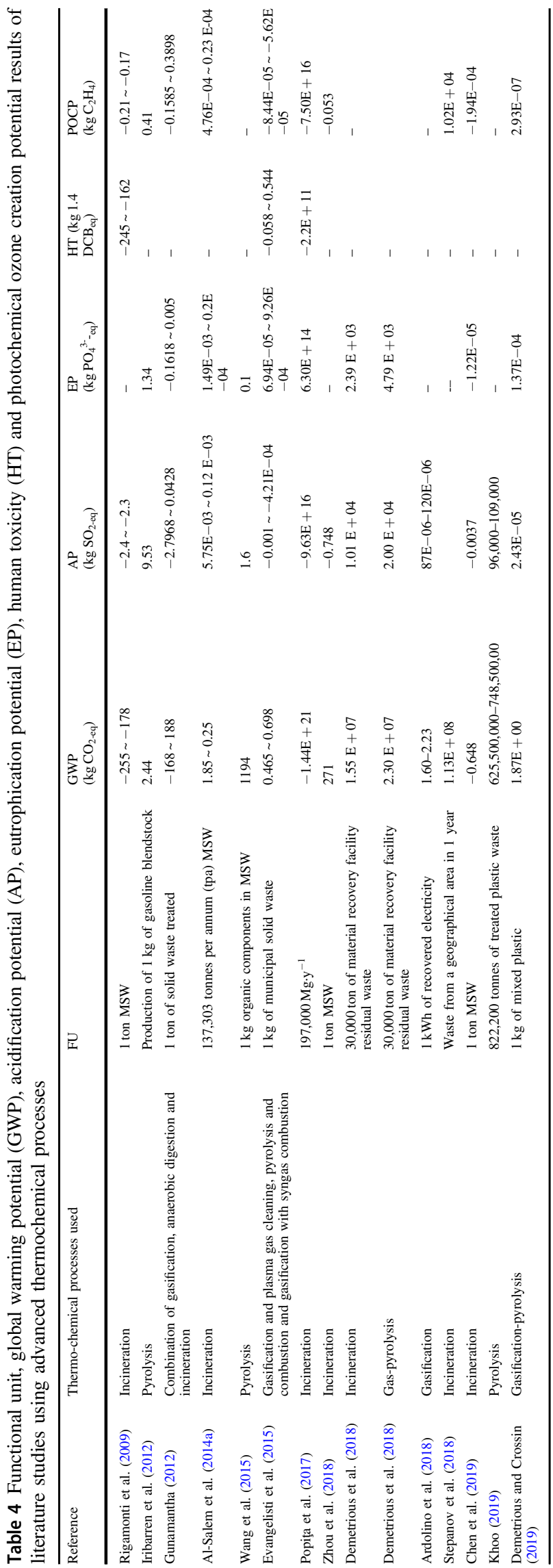

fluidized bed gasifier, fed with ten types of waste and biomass, under a wide range of operating conditions. The Crucial relationships between process- and waste-specific parameters were well-defined. The model quantifies the key inputs and outputs of the gasification process (emissions, energy recovery, ash disposal, resource consumptions), generating high-quality data that could contribute to advance life cycle assessment modelling of waste gasification. Lastly, some case studies were implemented in the EASETECH software to illustrate the model applicability, assess the role of main parameters, and compare the environmental performances of gasification power units with that of the European electricity mix. The performances seem to be largely affected by the metal contents in the waste-derived fuels, whilst the model results to a restricted extent are sensitive to the equivalence ratio and the net electrical efficiency of the energy conversion.

Demetrious et al. (2018) compared the alternative methods for managing the residual of material recovery facilities using LCA in Sydney, Australia. In this study, the environmental performance of the material recovery facilities' residual waste was evaluated using an LCA that approximates the potential impacts of acidification, climate change, eutrophication and photochemical oxidation. A sensitivity analysis established different waste fractions of material recovery facilities (MRF) residual waste composition. The results showed that landfill had the lowest GHG emissions irrespective of whether credits offset electricity, and of the carbon accounting methods used to measure biogenic carbon dioxide. It was also found that landfill had the lowest acidifying emissions, however, the waste-toenergy technologies performed better in diminishing eutrophying and photochemical oxidation emissions. Aggregated by normalization and weightings, landfilling was observed to have the lowest single score. The study conveyed electricity generation potentials through thermal turbine, synthetic gas engine and landfill gas combustion, and concluded incineration to have highest electricity generation potential, followed by gasification-pyrolysis.

\section{Major Findings, and Way Forward, Detailing Research Gaps in Area}

Astrup et al. (2015) reviewed 136 journal articles regarding the LCA of the waste to energy technologies such as; incineration, co-combustion, pyrolysis and gasification. They have analysed existing LCA studies to identify the most important methodological aspects and technology parameters, and to provide recommendations for the LCA assessments. Most of the case studies analysed incineration and only a few addressed pyrolysis. Not all papers provided detailed description of goal and scope of the assessment, the 
technologies included, and the calculation principles applied. Furthermore, in very few studies the reported results could be verified that limits the application of the inventory data and results. LCA guidelines outline the main assessment principles, but little methodological consistencies exist between LCA studies in literature. Results of the LCA studies based on similar waste type and technology vary considerably.

Some LCA studies suggest that the anaerobic digestion is preferable (e.g. Khoo 2009), while others favour waste incineration (e.g. Manfredi et al. 2011; Fruergaard and Astrup 2011). Therefore, the given guidelines still allow the room for interpretation (Laurent et al. 2014a, 2014b). Technology modelling principles, LCA principles, impact assessment methodologies and emission levels vary significantly between LCA studies (Laurent et al. 2014a). The detailed waste composition and type used in the study is important for the framework of the assessment. In the review by Astrup et al. (2015) only 70\% of the case-studies provided a detailed description of the material fractions present in the waste, while only $44 \%$ provided information about the chemical composition of the waste. The lack of detailed descriptions in the studies limits the LCA modelling as emissions are affected by the waste input composition. Few of the LCA studies provide enough description of the LCA modelling scope and of the technologies included in the assessment. Omitting the information limits the linking between the functional unit, the waste composition and the waste to energy technology assessed. Also, the key parameters such as air-pollution-control, residue management, and capital goods were omitted in many published past works. In the papers where the description of LCA modelling approaches is weak, the calculations cannot be reproduced or assessed for validity. This significantly limits the application of the LCA results for decision makers and limits the value of LCA studies for the implementation of waste to energy technologies in society. In order to evaluate the validity of the LCA conclusions, the studies should assess parameter and scenario uncertainties. Despite this, $46 \%$ of the case-studies do not include uncertainty assessments. Only $29 \%$ of the studies included sensitivity analysis on selected parameters, while scenario uncertainties were only evaluated in $41 \%$ cases (Astrup et al. 2015).

There have been various LCA studies conducted under protection and non-disclosure agreements that prohibit the public from knowing the end results. These include various major projects around the world that are concerned with commercial and urban development. Social and economic impacts are two main categories that need to be addressed in future studies concerning PSW management. Furthermore, one major impact that needs to be implemented in future studies is geographical location. Various processes and systems depend on the geographical location of a country or a production line, etc. This aspect, in combinations with the impact of various renewable energy resources that depend on the geographical location of many societies, can be added to the assessment categories in the near future.

\section{Conclusions and Recommendations}

Plastic solid waste remains one of the major concerns globally due to the environmental impact, as it can lead to long-term soil and groundwater pollution. Pre-treatment and recycling have been proven beneficial for reducing their impact, however, the increasing amounts of plastic waste and the low percentage used as recyclable plastic highlight the importance of post-treatment of the PSW. LCA is a developed tool for assessing the weight of environmental pollution and analysing the avoided burdens based on the processes taking place on waste management. The steadily increasing inventory (LCI) allows detailed analysis on the allocation of burdens and pollutants on each step of the waste management process, and the selection of the appropriate sustainable method. LCA studies are usually augmented via the sensitivity analysis studies for more detailed results on the behaviour of the concerned systems and the selection of the optimal process conditions or decreasing system uncertainty. Published studies on the environmental impact of PSW have shown that thermochemical post-treatments, such as gasification, incineration or pyrolysis, result to further decrease of the environmental effects, in comparison to landfilling. Furthermore, pyrolysis offers the advantage of bio-oil and char production of high calorific value, which can be used as fuels either for internal consumption of the plant or in other systems as substitution to fossil fuels. Hence, pyrolysis agrees with the environmental guidelines drawn by the ISO 14040 and 14044 standards to promote sustainable environmental solution on waste management. However, LCA is not univocally addressed for the environmental assessment, but is rather considered an integrated tool accounting for the life cycle cost of the proposed methodology and the overall process. Lack of market values on emissions and pyrolysis fuel products result to debatable results, which are subject to considered system boundaries, assumptions and functional unit. This review introduces pyrolysis as a studied and robust methodology for PSW post-treatment for minimization of the environmental burdens of the process, and emphasizes the importance of drawing a systematic scheme of LCA analysis on PSW management. Pyrolysis is an advanced waste treatment technique and this review has potentially a key role to play on the development of a strategic planning in which all advantages of pyrolysis will be considered. 
Acknowledgements The authors are grateful to the blind reviewers for their technical feedback and insightful input, which made this communication more technically sound and thorough.

\section{Compliance with Ethical Standards}

Conflict of Interest The authors declare that they have no conflict of interest.

Publisher's note: Springer Nature remains neutral with regard to jurisdictional claims in published maps and institutional affiliations.

Open Access This article is distributed under the terms of the Creative Commons Attribution 4.0 International License (http://crea tivecommons.org/licenses/by/4.0/), which permits unrestricted use, distribution, and reproduction in any medium, provided you give appropriate credit to the original author(s) and the source, provide a link to the Creative Commons license, and indicate if changes were made.

\section{References}

4R Sustainability, Inc. (2011) Conversion technology: a complement to plastic recycling. https://plastics.americanchemistry.com/Pla stics-to-Oil/

Agilyx (2019) Driving innovations to make plastics a renewable resource. https://www.agilyx.com/. Accessed 25 Mar 2019

Aguado J, Serrano DP, Escola JM, Garagorri E, Fernandez JA (2000) Catalytic conversion of polyolefins into fuels over Zeolite beta. Polym Degrad Stab 69(1):11-16

Al-Fadhlee AA, Al-Salem, SM (2015) Life cycle assessment (LCA) of plastic solid waste (PSW) integrated feed to existing oil refineries in the state of Kuwait. In: Proc 7th Kuwait Waste Management \& Recycling Conference \& Exhibition. Kuwait City, State of Kuwait, 18th-19th April

Almeida D, Marques M (2016) Thermal and catalytic pyrolysis of plastic waste. Polímeros 26(1):44-51. https://doi.org/10.1590/ 0104-1428.2100

Al-Salem SM, Lettieri P, Baeyens J (2009) Recycling and recovery routes of plastic solid waste (PSW): a review. Waste Manag 29 (10):2625-2643

Al-Salem S, Evangelisti S, Lettieri P (2014a) Life cycle assessment of alternative technologies for municipal solid waste and plastic solid waste management in the Greater London area. Chem Eng J 244:391-402. https://doi.org/10.1016/j.cej.2014.01.066

Al-Salem SM (2014b) Life cycle assessment (LCA) of thermochemical treatment (TCT) technologies integrated to oil refineries in Kuwait. In: Proc 3rd Kuwait Conference of Chemistry (KCC), Kuwait City, State of Kuwait, 9th-11th March, p 37

Al-Salem SM, Abraham G, Al-Qabandi OA, Dashti AM (2015) Investigating the effect of accelerated weathering on the mechanical and physical properties of high content plastic solid waste (PSW) blends with virgin linear low density polyethylene (LLDPE). Polym Test 46:116-121. https://doi.org/10.1016/j. polymertesting.2015.07.008

Al-Salem SM, Antelava A, Constantinou A, Manos G, Dutta A (2017) A review on thermal and catalytic pyrolysis of plastic solid waste (PSW). J Environ Manag 197:177-198. https://doi.org/10.1016/j. jenvman.2017.03.084

Ardolino F, Lodato C, Astrup TF, Arena U (2018) Energy recovery from plastic and biomass waste by means of fluidized bed gasification: a life cycle inventory model. Energy 165:299-314
Arena U, Mastellone ML, Perugini F (2003) The environmental performance of alternative solid waste management options: a life cycle assessment study. Chem Eng J 96:207-222. https://doi.org/ 10.1016/j.cej.2003.08.019

Astrup T, Tonini D, Turconi R, Boldrin A (2015) Life cycle assessment of thermal Waste-to-Energy technologies: review and recommendations. Waste Manag 37:104-115

Bailey MP (2014) Advanced polymer recycling. Chem Eng 121(3):17

Barry D, Barbiero C, Briens C, Berruti F (2019) Pyrolysis as an economical and ecological treatment option for municipal sewage sludge. Biomass Bioenerg 122:472-480. https://doi.org/10.1016/ j.biombioe.2019.01.041

Begum S, Rasul MG, Cork D, Akbar D (2014) An experimental investigation of solid waste gasification using a large pilot scale waste to energy plant. Procedia Eng 90:718-724. https://doi.org/ 10.1016/j.proeng.2014.11.802

Benavides P, Sun P, Han J, Dunn J, Wang M (2017) Life-cycle analysis of fuels from post-use non-recycled plastics. Fuel 203:11-22. https://doi.org/10.1016/j.fuel.2017.04.070

Blengini G, Fantoni M, Busto M, Genon G, Zanetti M (2012) Participatory approach, acceptability and transparency of waste management LCAs: Case studies of Torino and Cuneo. Waste Manag 32(9): 1712-1721

Borgianni C, Filippis PD, Pochetti F, Paolucci M (2002) Gasification process of wastes containing PVC. Fuel 81(14):1827-1833

Bovea MD, Ibáñez-Forés V, Gallardo A, Colomer-Mendoza FJ (2010) Environmental assessment of alternative municipal solid waste management strategies. A Spanish case study. Waste Manag 30:2383-2395. https://doi.org/10.1016/j.wasman.2010.03.001

Bringezu S, Schütz H, Arnold K, Merten F, Kabasci S, Borelbach P, Michels C, Reinhardt GA, Rettenmaier N (2009) Global implications of biomass and biofuel use in Germany- recent trends and future scenarios for domestic and foreign agricultural land use and resulting GHG emissions. J Clean Prod 17(1):57-68

Butler E, Devlin G, McDonnell K (2011) Waste polyolefins to liquid fuels via pyrolysis: review of commercial state-of-the-art and recent laboratory research. Waste Biomass Valori 2(3):227-255

Cabeza LF, Vilariño LRV, Pérez G, Castell A (2014) Life cycle assessment (LCA) and life cycle energy analysis (LCEA) of buildings and the building sector: a review. Renew Sust Energ Rev 29:394-416. https://doi.org/10.1016/j.rser.2013.08.037

Chen D, Yin L, Wang H, He P (2014) Pyrolysis technologies for municipal solid waste: a review. Waste Manag 34(12):2466-2486

Chen G, Wang X, Li J, Yan B, Wang Y, Wu X, Velichkova R, Cheng Z, Ma W (2019) Environmental, energy, and economic analysis of integrated treatment of municipal solid waste and sewage sludge: a case study in China. Sci Total Environ 647:1433-1443

Cheng H, Hu Y (2010) Municipal solid waste (MSW) as a renewable source of energy: current and future practices in China. Bioresour Technol 101(11):3816-3824

Ciliz NK, Ekinci E, Snape CE (2004) Pyrolysis of virgin and waste polyethylene and its mixtures with waste polyethylene and polystyrene. Waste Manag 24(2):173-181

Clift R, Doig A, Finnveden G (2000) The application of life cycle assessment to integrated waste management. Part 1-Methodology. Process Saf Environ 78(4B):279-287

Collet P, Spinelli D, Lardon L, Hélias A, Steyer JP, Bernard O (2013) Life-cycle assessment of microalgal-based biofuels. In: Pandey A, Lee DJ, Chisti Y, Soccol CR (eds) Biofuels from algae, 1st edn. Elsevier, pp 287-312

Demetrious A, Verghese K, Stasinopoulos P, Crossin E (2018) Comparison of alternative methods for managing the residual of material recovery facilities using life cycle assessment. Resour Conserv Recycl 136:33-45

Demetrious A, Crossin E (2019) Life cycle assessment of paper and plastic packaging waste in landfill, incineration, and gasification- 
pyrolysis. J Mater Cycles Waste Manag 1-11, https://doi.org/10. 1007/s10163-019-00842-4

Demirbas A (2004) Pyrolysis of municipal plastic wastes for recovery of gasoline range hydrocarbons. J Anal Appl Pyrolysis 72 (1):97-102

Dormer A, Finn DP, Ward P, Cullen J (2013) Carbon footprint analysis in plastics manufacturing. J Clean Prod 51:133-141. https:// doi.org/10.1016/j.jclepro.2013.01.014

Eia.gov (2019) U.S. Energy Information Administration (EIA). https://www.eia.gov/tools/faqs/faq.php?id=33\&t=6. Accessed 25 Mar 2019

Enval (2019) Plant enval. http://www.enval.com/plant/. Accessed 25 Mar 2019

ETIA Group (2019) Pyrolysis, torrefaction, gasification, carbonisationBiogreen $^{\circledast}$. http://etia-group.com/our-products/biogreen-pyrolysis/. Accessed 25 Mar 2019

Eriksson O. Finnvedenb G (2009) Plastic waste as a fuel- $\mathrm{CO}_{2}$-neutral or not? Energy Environ Sci (2):907-914. https://doi.org/10.1039/ b908135f

Eriksson O, Carlsson Reich M, Frostell B, Björklund A, Assefa G, Sundqvist JO, Granath J, Baky A, Thyselius L (2005) Municipal solid waste management from a systems perspective. J Clean Prod 13(3):241-252

Eriksson O, Frostell B, Björklund A, Assefa G, Sundqvist JO, Granath J, Carlsson M, Baky A, Thyselius L (2002) ORWARE-a simulation tool for waste management. Resour Conserv Recycl 36(4):287-307

Evangelisti S, Tagliaferri C, Clift R, Lettieri P, Taylor R, Chapman C (2015) Life cycle assessment of conventional and two-stage advanced energy-from-waste technologies for municipal solid waste treatment. J Clean Prod 100:212-223. https://doi.org/10. 1016/j.jclepro.2015.03.062

Fruergaard T, Astrup T (2011) Optimal utilization of waste-to-energy in an LCA perspective. Waste Manag 31(3):572-582

Garcia-Serna J, Pérez-Barrigón L, Cocero MJ (2007) New trends for design towards sustainability in chemical engineering: Green engineering. Chem Eng J 133(1-3):7-30

Gardy J, Hassanpour A, Lai X, Rehan M (2014) The influence of blending process on the quality of rapeseed oil-used cooking oil biodiesels. J Environ Sci 3:233-240

Gear M, Sadhukhan J, Thorpe R, Clift R, Seville J, Keast M (2018) A life cycle assessment data analysis toolkit for the design of novel processes-A case study for a thermal cracking process for mixed plastic waste. J Clean Prod 180:735-747. https://doi.org/10.1016/ j.jclepro.2018.01.015

Geyer R, Jambeck JR, Law KL (2017) Production, use, and fate of all plastics ever made. Sci Adv 3(7):e1700782

Gu F, Guo J, Zhang W, Summers P, Hall P (2017) From waste plastics to industrial raw materials: a life cycle assessment of mechanical plastic recycling practice based on a real-world case study. Sci Total Environ 601-602:1192-1207. https://doi.org/10.1016/j. scitotenv.2017.05.278

Gunamantha M (2012) Life cycle assessment of municipal solid waste treatment to energy options: Case study of KARTAMANTUL region, Yogyakarta. Renew Energ 41:277-284

Haig S, Morrish L, Morton R, Onwuamaegbu U, Speller P, Wilkinson S (2017) Plastics to oil products. Axionconsulting, Bramhall, Cheshire, UK

Heras F, Jimenez-Cordero D, Gilarranz MA, Alonso-Morales N, Rodriguez JJ (2014) Activation of waste tire char by cyclic liquid-phase oxidation. Fuel Process Technol 127:157-162. https://doi.org/10.1016/j.fuproc.2014.06.018

Hertwich EG, Pennington DW, Bare JC (2002) Introduction. In: Udo de Haes HA, et al. (eds) Life-cycle impact assessment: striving towards best practice. Setac Press, Brussels, ISBN 1-880611-54-6
Iribarren D, Dufour J, Serrano DP (2012) Preliminary assessment of plastic waste valorization via sequential pyrolysis and catalytic reforming. J Mater Cycles Waste 14(4):301

Islam MR, Parveen M, Haniu H, Sarker MI (2010) Innovation in pyrolysis technology for management of scrap tire: a solution of Energy and Environment. J Environ Dev 1(1):89

ISO 14040 (1997) International Standard Organization, ISO 14040: Environmental Management-Life Cycle Assessment-Principles and Framework

ISO 14040 (2006) International Standard Organization, ISO 14040: Environmental management-Life cycle assessment-Principles and Framework

ISO 14066 (2011) International Standard Organization, ISO 14066: Greenhouse gases-Competence requirements for greenhouse gas validation teams and verification teams

ISO 14071 (2014) International Standard Organization, ISO/TS 14071: Environmental management-Life cycle assessmentCritical review processes and reviewer competencies: Additional requirements and guidelines to ISO 14044:2006

ISO 14072 (2014) International Standard Organization, ISO/TS 14072: Environmental management-Life cycle assessment-Requirements and guidelines for organizational life cycle assessment

ISO 15270 (2008) International Standard Organization, ISO 15270: Plastics - Guidelines for the recovery and recycling of plastics waste

Jindaporn J, Lertsatitthanakorn C (2014) Characterization and utilization of char derived from fast pyrolysis of plastic wastes. Adv Mater Res 69:1437-1442. https://doi.org/10.4028/www. scientific.net/AMR.931-932.849

Khoo HH (2019) LCA of plastic waste recovery into recycled materials, energy and fuels in Singapore. Resour Conserv Recycl 145:67-77. https://doi.org/10.1016/j.resconrec.2019.02.010

Khoo HH (2009) Life cycle impact assessment of various waste conversion technologies. Waste Manag 29(6):1892-1900

Klean Industries (2019) Large scale plastics pyrolysis system to diesel fuel. http://www.kleanindustries.com/s/sapporo_plastics_ pyrolysis_recycling_plant.asp. Accessed 25 Mar 2019

Laurent A, Bakas I, Clavreul J, Bernstad A, Niero M, Gentil E, Hauschild MZ, Christensen TH (2014a) Review of LCA studies of solid waste management systems-Part I: Lessons learned and perspectives. Waste Manag 34(3):573-588

Laurent A, Clavreul J, Bernstad A, Bakas I, Niero M, Gentil E, Christensen TH, Hauschild MZ (2014b) Review of LCA studies of solid waste management systems-Part II: Methodological guidance for a better practice. Waste Manag 34(3):589-606

Lazarevic D, Aoustin E, Buclet N, Brandt N (2010) Plastic waste management in the context of a European recycling society: Comparing results and uncertainties in a life cycle perspective. Resour Conserv Recycl 55(2):246-259

Li C, Zhuang H, Hsieh L, Lee W, Tsao M (2001) PAH emission from the incineration of three plastic wastes. Environ Int 27 (1):61-67

Lopez A, De Marco I, Caballero BM, Laresgoiti MF, Adrados A (2011) Influence of time and temperature on pyrolysis of plastic wastes in a semi-batch reactor. Chem Eng J 173(1):62-71

Madival S, Auras R, Singh S. P, Narayan R (2009) Assessment of the environmental profile of PLA, PET and PS clamshell containers using LCA methodology. J Clean Prod 17(13):1183-1194. https://doi.org/10.1016/j.jclepro.2009.03.015

Makuta M, Moriguchi Y, Yasuda Y, Sueno S (2000) Evaluation of the effect of automotive bumper recycling by life-cycle inventory analysis. J Mater Cycles Waste 2(2):125-137

Manfredi S, Pant R, Pennington D, Versmann A (2011) Supporting environmentally sound decisions for waste management with LCT \& LCA. Int J Life Cycle Assess 16(9):937-939 
Margallo M, Aldaco R, Bala A et al. (2018) Contribution to closing the loop on waste materials: valorization of bottom ash from wasteto-energy plants under a life cycle approach. J Mater Cycles Waste 20(3):1507-1515

Melnyk A, Dettlaff A, Kuklińska K, Namieśnik J, Wolska L (2015) Concentration and sources of polycyclic aromatic hydrocarbons (PAHs) and polychlorinated biphenyls (PCBs) in surface soil near a municipal solid waste (MSW) landfill. Sci Total Environ 530-531:18-27. https://doi.org/10.1016/j.scitotenv.2015.05.092

Miandad R, Barakat MA, Aburiazaiza AS, Rehan M, Nizami AS (2017) Effect of plastic waste types on pyrolysis liquid oil. Int Biodeterior Biodegradation 119:239-252

Miandad R, Barakat MA, Aburiazaiza AS, Rehan M, Nizami AS (2016) Catalytic pyrolysis of plastic waste: a review. Process Saf Environ 102:822-838. https://doi.org/10.1016/j.psep.2016. 06.022

Milne TA, Evans RJ (1998) Biomass gasifier tars: their nature, formation, and conversions. National Renewable Energy Laboratory, Golden, CO, NREL/TP570-2535

Nizami AS, Rehan M, Ouda OK, Shahzad K, Sadef Y, Iqbal T, Ismail IM (2015) An argument for developing waste-to-energy technologies in Saudi Arabia. Chem. Eng. Trans 45:337-342. https:// doi.org/10.3303/CET1545057

Panda A, Singh R, Mishra D (2010) Thermolysis of waste plastics to liquid fuel. A suitable method for plastic waste management and manufacture of value added products-A world prospective. Renew Sust Energ Rev 14(1):233-248

Panepinto D, Tedesco V, Brizio E, Genon G (2015) Environmental performances and energy efficiency for MSW gasification treatment. Waste Biomass Valori 6(1):123-135

PE (2016) Plastics Europe, Association of Plastics Manufacturers, An analysis of European plastics, demand and waste data.

Plastic Energy (2019) Plastic energy https://plasticenergy.com/. Accessed 25 Mar 2019

Plastic2oil (2019) Plastic2Oil Inc. http://www.plastic2oil.com/site/a dvantage. Accessed 25 Mar 2019

Popiţa GE, Baciu C, Rédey Á, Frunzeti N, Ionescu A, Yuzhakova T, Popovici, A (2017) Life cycle assessment (lca) of municipal solid waste management systems in Cluj county, Romania. Environ Eng Manag J 16(1):47-57

Recycling Technologies (2019) https://recyclingtechnologies.co.uk/. Accessed 26 Mar 2019

Rigamonti L, Grosso M, Giugliano M (2009) Life cycle assessment for optimising the level of separated collection in integrated MSW management systems. Waste Manag 29(2):934-944. https://doi. org/10.1016/j.wasman.2008.06.005
Seth D, Sarkar A (2004) Thermal pyrolysis of polypropylene: effect of reflux-condenser on the molecular weight distribution of products. Chem Eng Sci 59(12):2433-2445

Sheth P, Babu BV (2009) Differential evolution approach for obtaining kinetic parameters in nonisothermal pyrolysis of biomass. Mater Manuf Process 24(1):47-52

Song H, Hyun J (1999) A study on the comparison of the various waste management scenarios for PET bottles using the life-cycle assessment (LCA) methodology. Resour Conserv Recycl 27 (3):267-284

Stepanov J, Ubavin DE, Prokic DU, Budak I, Stevanovic-Carapina HR, Stanisavljevic NE (2018) Comparison of municipal waste management systems using LCA. South Backa waste management region. A case study. Environ Prot Eng 44(3):33-49

Syamsiro M, Saptoadi H, Norsujianto T, Noviasri Cheng S, Alimuddin Z, Yoshikawa K (2014) Fuel oil production from Municipal plastic wastes in sequential pyrolysis and catalytic reforming reactors. Energy Procedia 47:180-188. https://doi.org/10.1016/j. egypro.2014.01.212

Syngas Products Group (2019) https://syngas-products.com/. Accessed 26 Mar 2019

Tarantini M, Loprieno A, Cucchi E, Frenquellucci F (2009) Life cycle assessment of waste management systems in Italian industrial areas: case study of 1st Macrolotto of Prato. Energy 34(5):613-622

US EPA (2019) National Overview: Facts and Figures on Materials, Wastes and Recycling I US EPA. https://www.epa.gov/facts-andfigures-about-materials-waste-and-recycling/national-overview-fa cts-and-figures-materials\#Landfilling. Accessed 27 Mar 2019

Verma R, Vinoda KS, Papireddy M, Gowda ANS (2016) Toxic pollutants from plastic waste-a review. Procedi Environ Sci 35:701-708. https://doi.org/10.1016/j.proenv.2016.07.069

Vienescu DN, Wang J, Le Gresley A, Nixon JD (2018) A life cycle assessment of options for producing synthetic fuel via pyrolysis. Bioresour Technol 249:626-634. https://doi.org/10.1016/j. biortech.2017.10.069

Wang H, Wang L, Shahbazi A (2015) Life cycle assessment of fast pyrolysis of municipal solid waste in North Carolina of USA. J Clean Prod 87:511-519

Zaman AU (2013) Life cycle assessment of pyrolysis-gasification as an emerging municipal solid waste treatment technology. International Journal of Environmental Science and Technology 10 (5): $1029-1038$

Zhou Z, Tang Y, Dong J, Chi Y, Ni M, Li N, Zhang Y(2018) Environmental performance evolution of municipal solid waste management by life cycle assessment in Hangzhou, China. J Environ Manag 227:23-33 